\title{
Miradas etnográficas y representaciones de ciudadanía en jóvenes indígenas, migrantes purépechas de México
}

\author{
Alberto Farías Ochoa ${ }^{1}$
}

Fecha de recepción: 11 de julio de 2018

Fecha de aprobación: 09 de noviembre de 2018

\begin{abstract}
Resumen
El presente artículo tiene el propósito de reportar, a través de una investigación etnográfica, la situación actual de algunos jóvenes indígenas migrantes del pueblo purépecha de México, los cuales han crecido toda su corta vida en el seno de una familia de tipo indocumentada en Estados Unidos y quienes, por condiciones políticas y laborales, han debido regresar, junto a sus familias, a instalarse en su comunidad purépecha de origen. Se hace énfasis en la condición de los jóvenes, específicamente los involucrados con el Programa DACA, debido a que son ellos los que se reconocen más vulnerables al regresar a su comunidad indígena, y es que las condiciones estructurales de una sociedad que no ha dispuesto las oportunidades necesarias para su reincorporación como repatriados, generan en ellos tendencias a la segregación espacial e institucional en su propio país. En este trabajo se hace también un señalamiento a la falta de efectividad en las estrategias del Estado mexicano y de sus instituciones para la reintegración social de los jóvenes migrantes purépechas que, por diferentes circunstancias, han dejado la Unión Americana y han regresado a su país de origen.
\end{abstract}

Palabras clave: etnografía y migraciones, jóvenes indígenas, ciudadanía e identidad.

\section{Ethnographic looks and citizenship representations in migrant indigenous purépechas youth in Mexico}

\begin{abstract}
This article is aimed at reporting through ethnographic research, the current situation of some young indigenous migrants of Purepecha People in Mexico. They have grown all their short life within an undocumented family
\end{abstract}

Doctor por la Universidad Pedagógica Nacional, México. Profesor Investigador Asociado de la Universidad Michoacana de San Nicolás de Hidalgo. Morelia, Michoacán, México. Contacto: farias.ellh@gmail.com 
Miradas etnográficas y representaciones de ciudadanía en jóvenes indígenas, migrantes purépechas de México - Farías

in the United States and - for political and labor conditions - they have had to return, together with their families, to settle in their Purépecha community of origin. Emphasis is placed on their conditions, specifically for those involved in the DACA Program, because they recognize themselves as the most vulnerable when returning to their indigenous community, and that is the structural conditions of a society that does not have opportunities for their reintegration, as returnees, generating in them a tendency to spatial and institutional segregation in their own country. In this paper, we also show the ineffectiveness of strategies from the Mexican State, and its institutions, for the social reintegration of Purepecha young migrants who, for different reasons, have left the American Union to return to their country of origin.

Keywords: Ethnography and migrations, indigenous youth, citizenship and identity.

\title{
Olhares etnográficos e representações de cidadania em jovens indígenas, migrantes purépechas do México
}

\begin{abstract}
Resumo
O presente artigo tem o propósito de informar através de uma pesquisa etnográfica, a situação atual de alguns jovens indígenas migrantes do Povo Purépecha do México, os quais têm crescido toda sua curta vida no seio de uma família de tipo indocumentada nos Estados Unidos, e por condições políticas e laborais têm tido que regressar, junto a suas famílias, a se instalarem em sua comunidade purépecha de origem. Põe-se ênfase na condição dos jovens, nomeadamente os envolvidos no Programa DACA, devido a que são eles os que se reconhecem mais vulneráveis ao regressarem a sua comunidade indígena, e é que as condições estruturais de uma sociedade que não tem oferecido as oportunidades necessárias para sua reincorporação, como repatriados, geram neles tendências à segregação espacial e institucional no seu próprio país. Neste trabalho faz-se também uma indicação à falta de efetividade nas estratégias do Estado Mexicano, e de suas instituições, para a reintegração social dos jovens migrantes purépechas que por diferentes circunstâncias têm deixado a União Americana e têm regressado a seu país de origem.
\end{abstract}

Palavras-chave: etnografia e migrações, jovens indígenas, cidadania e identidade.

\section{Introducción}

La investigación que en este artículo se reporta persigue como objetivo identificar las experiencias que los jóvenes indígenas purépechas de Michoacán refieren en su calidad de migrantes laborales en retorno a sus comunidades de origen. Lo anterior como parte de un conglomerado de hijos de primeros migrantes 
que se han desarrollado en su infancia y adolescencia en Estados Unidos y que poco conocen de su país natal. A estos jóvenes se les ha conocido como "dreamers" o "jóvenes DACA". Particularmente interesa a la investigación analizar, desde la experiencia narrativa de los propios jóvenes indígenas, aquellos elementos que apunten hacia el ejercicio de la ciudadanía en los migrantes purépechas en retorno, así como las prerrogativas que, en su calidad de mexicanos, encuentran o no para el desarrollo de sus expectativas y preocupaciones.

A los llamados "dreamers"2 se les identificó como uno de los primeros grupos vulnerables ante el cambio de presidencia en Estados Unidos, y es que, a decir de Flores, desde sus inicios la administración de Donald Trump fue enfática en la suspensión de diferentes garantías para las comunidades migrantes y también para sus hijos (Flores, 2016). Entre estos hijos de migrantes, quienes principalmente vieron suspendidos sus derechos de estudio y trabajo, se identifican varios jóvenes pertenecientes a la etnia indígena purépecha de Michoacán, y son ellos de quienes interesa recabar su experiencia y sus señalamientos que apunten hacia un reconocimiento del ejercicio de su ciudadanía como mexicanos.

A través de diferentes técnicas de recopilación y registro de las experiencias, entre las que destacan la entrevista a profundidad y la observación in situ, se propiciaron diálogos con los jóvenes participantes en este primer estudio durante los últimos meses de 2017 y los primeros de 2018; lo anterior tuvo lugar en las propias localidades purépechas de origen de los jóvenes participantes, tales como Angahuan, Cherán, Paracho y Zacán, todas en el Estado de Michoacán, México. La incorporación de estas técnicas corresponde a un recorrido de recopilación de

Término empleado principalmente por la prensa de Estados Unidos para llamar a jóvenes inmigrantes llegados en calidad de infantes a la Unión Americana, con derechos de educación y posibilidades de empleo reconocidos a través del programa Acción Diferida para los Llegados en la Infancia (DACA por sus siglas en inglés). 
corte etnográfico, que pretende dar evidencia de la experiencia mediante el relato, en el que pueden tener lugar negociaciones de significado ante los elementos dispuestos para repensar la ciudadanía.

El discurso de la migración en la población indígena de Michoacán, México, es un elemento constante de dimensiones no sólo económicas, sino políticas, culturales y comunitarias. Desde la primera mitad del siglo XX esta población reconoce la migración hacia Estados Unidos como una de las alternativas posibles de prosperidad económica y, desde temprana edad, las nuevas generaciones se forman una idea de lo que representa migrar para trabajar "al Norte". El contacto de los residentes de las comunidades indígenas con los connacionales que se encuentran laborando en el vecino país es permanente, y está determinado principalmente por las remesas que son enviadas a las familias, mes con mes, así como por los festejos tradicionales de cada comunidad.

La región de la Meseta Purépecha, lugar en donde se centran las observaciones de esta investigación de corte etnográfico, se sitúa en la zona volcánica del Estado de Michoacán en México, y es reconocida por su población mayoritariamente indígena, la que se desarrolla en actividades económicas como la explotación silvícola de los bosques, la agricultura, el turismo y la elaboración de artesanías. Dichas actividades, aunque son reconocidas como principales ocupaciones formales, son insuficientes para la manutención y crecimiento económico de las familias, lo que propicia la búsqueda de alternativas de movilidad para el trabajo, como la migración nacional e internacional (Farías, 2017, p. 69).

Otra característica de la población indígena residente de la meseta purépecha es la preservación de su lengua originaria (lengua p'urhépecha), la cual, en la mayoría de los municipios de la región, es apropiada como lengua materna para su empleo, enseñanza y transformación en las actividades cotidianas de su vida, incluso en aquellas actividades dependientes de las estruc- 
turas institucionales del Estado mexicano, como las de educación básica, las de salud y las de procuración de justicia. En el aspecto lingüístico de las comunidades purépechas, las autoridades mexicanas han enfrentado un desafío todavía no resuelto, que se refiere al respeto y al fomento de la lengua originaria, al mismo tiempo que han quedado pendientes las garantías y condiciones necesarias en las estructuras de atención pública, que sean incluyentes para aquellos hablantes nativos del p'urhépecha que no son hablantes del español.

El empleo de la lengua p'urhépecha, y la incorporación del español como segunda lengua, es claramente una de las aristas que más dan evidencia de la discriminación que día a día suele vivir esta población indígena en cuestión; se da así en diferentes dimensiones y en detrimento de sus prerrogativas como ciudadanos mexicanos. Como ejemplo se tiene el acceso a la educación superior, la atención en hospitales de especialidad, la incorporación al sector industrial y el derecho a un juicio imparcial ante las instancias penales, todos derechos que solamente se otorgan de manera óptima al hablante de lengua española. Dicho panorama ha propiciado un acotamiento de oportunidades de desarrollo y de plena vida para el ciudadano p'urhépecha, lo que a su vez se refleja en condiciones permanentes de inequidad y discriminación, orillando así a gran cantidad de indígenas purépechas a buscar oportunidades en otras geografías.

A pesar de que la migración indígena purépecha hacia Estados Unidos se presume desde las primeras décadas del siglo XX, no es sino hasta los años 40 cuando, a través del Programa Bracero, se comienza a tener registro y noción cuantitativa del fenómeno (Leco, 2009, p. 24). El Programa Bracero consistió en una oferta de trabajo temporal en 1942 del gobierno de Estados Unidos a jornaleros agrícolas mexicanos, porque dadas las actividades bélicas en Asia y Europa, que ocupaban la atención del gobierno norteamericano, se precisaba en aquella nación de mano de obra capacitada para mantener la productividad de los cultivos, los cuales cada vez tenían más demanda debido 
a las necesidades de consumo dentro y fuera de aquel país. A partir de este referente, muchos trabajadores agrícolas mexicanos construyeron redes de ocupación laboral con empleadores americanos, lo que representó una oportunidad de crecimiento económico para cada vez más trabajadores mexicanos. Así, dicha realidad fue creciendo hasta las proporciones evidentes en esta segunda década del siglo XXI.

El tema retoma importancia para su análisis debido al recrudecimiento, en los últimos 20 años, de las acciones racistas en contra de trabajadores mexicanos por parte de un sector cada vez mayor en la Unión Americana (Aquino, 2015, p. 79). Dichos ataques se perpetran por medio de la violencia en las calles, y también se presentan en formatos sutiles y legales, pero igualmente hostiles, como es el caso de las iniciativas impulsadas por el actual presidente Donald Trump y un sector representativo del Senado. Con este panorama, se matiza el énfasis que persigue esta investigación, concretamente a través de los sujetos de estudio representados por jóvenes indígenas migrantes que se vieron obligados a regresar a sus comunidades originarias ante la falta de garantías de seguridad y oportunidades. Algunos de estos jóvenes se reconocen incluso como estudiantes beneficiados, en su momento, por el programa de Acción Diferida de la Deportación para los Menores (DACA), pero que ahora han visto frustradas sus posibilidades de crecimiento debido al endurecimiento del ejercicio punitivo en contra de la población hispana en Estados Unidos.

Con este marco de antecedentes, toma forma la pregunta central que orienta este trabajo de investigación, la cual se enuncia de la siguiente manera: ¿Cuál es la experiencia en el ejercicio de la ciudadanía de los jóvenes migrantes purépechas, alguna vez pertenecientes al programa DACA, ante su regreso como residentes de sus comunidades indígenas de origen, y qué garantías les ofrece el país que los vio nacer en función de sus expectativas y preocupaciones? 


\section{Jóvenes indígenas DACA: ilusión, frustración e identidad}

Los jóvenes purépechas que fueron llevados en calidad de migrantes a la Unión Americana durante la década de los 90 se caracterizan por su desarrollo durante la infancia y adolescencia en familias de condiciones legales mixtas; esto significa que algunos miembros de la familia tienen derecho a la residencia, otros incluso aspiran a la ciudadanía y otros son simplemente indocumentados. Este referente toma importancia si se considera que, debido a su condición de infantes y gracias a los tratados internacionales de derechos humanos, la mayoría de ellos fueron beneficiados por el sistema de educación básica y por el sistema de atención a la salud estadounidense, pero, al mismo tiempo, estos mismos niños observaron la negación de estos y otros servicios para sus padres y familiares con quienes compartían su vida. Así, desde los primeros años, esta generación pudo dar evidencia de las condiciones de desigualdad que se apreciaban en el entorno al que ellos pertenecían.

Dadas las condiciones de interculturalidad en los lugares de residencia de familias migrantes en las ciudades norteamericanas, las desigualdades suelen ser fácilmente apreciables mediante la convivencia cotidiana. Desde el empleo de la lengua, por ejemplo, se marcan profundas diferencias, que reflejan no solamente el dominio de un acervo lingüístico, sino la manera de comprender el mundo y la cosmovisión sobre los tiempos a los que se corresponden. Dichas diferencias, reflejadas por la posesión (en diferentes niveles) de la lengua, o lenguas, son vividas en la práctica del niño purépecha migrante en la comunidad, en su relación con sus autoridades escolares, con sus pares, con los prestadores de servicios, con los miembros del vecindario y, por supuesto, al interior de su propia casa. El caso común de los hogares de esta naturaleza es con la instrucción de los infantes en el aprendizaje del inglés, pero con padres que son hablantes nativos del P'urhépecha y que comprenden de manera funcional el 
español, en algunos casos incluso los padres no saben escribir el español.

La posesión de la lengua (en cualquiera de sus variantes) es un eje clave para comprender la mirada de los jóvenes purépechas migrantes, y es que la mayoría de ellos no reconoce como lengua materna la P'urhépecha; algunos de ellos ni siquiera la comprenden, pero tampoco dominan el español, y sí se reconocen presionados para adquirir el inglés y así abrirse paso en las pocas oportunidades en las que encuentran cabida para crecer en un país que tampoco reconocen como propio. Como se puede comprender, estas diferenciaciones lingüísticas son, por sí mismas, variables que propician diferentes actos de discriminación y segregación incluso al interior de la propia familia, más aún cuando los jóvenes, en su natural deseo de integración social, privilegian, a través de sus prácticas, su identificación con otros jóvenes de similares condiciones por encima de los propios miembros de su familia. De la O explica que este tipo de escenarios forma parte de una realidad muy común en las condiciones de coyuntura los también conocidos como "dreamers" De la O (2017, pp. 35-39).

Una de las ventajas que a los jóvenes dreamers otorgó la adquisición del inglés, fue la de avanzar en la estructura de educación pública norteamericana, apropiando saberes, costumbres y también paradigmas; algunos de estos jóvenes incluso fueron capaces de culminar los estudios de preparatoria (la highschool) y solicitar ingreso a algún colegio del Estado, o bien a una universidad. Fue gracias a iniciativas como la Acción Diferida de la Deportación para los Menores (DACA) en 2012, impulsada por el entonces presidente de los Estados Unidos de América Barack Obama, que algunos jóvenes hispanos en calidad de migrantes vieron la oportunidad de matricularse y concluir sus estudios en una institución de educación superior. DACA otorgaba a los jóvenes hispanos migrantes, mediante decreto presidencial pero no por mandato constitucional, permisos temporales para estudiar y trabajar, con las garantías de la no deportación si se acreditaban todos los requisitos establecidos en el programa. De acuerdo con 
la prensa estadounidense, se estima que en 2016 se tenía registro de 752.000 jóvenes beneficiarios del programa DACA, provenientes de varios países, entre los que destacan en número los jóvenes mexicanos, y entre los cuales, con muchos esfuerzos, se logró identificar jóvenes originarios de las comunidades purépechas.

Como se temía desde un principio respecto de los resultados de DACA, el programa fue solamente una medida de satisfacción temporal para los jóvenes, y es que al tratarse de una "acción ejecutiva" del entonces presidente Barack Obama y no de un mandato constitucional, se sujetaba en su vigencia a una nueva decisión ejecutiva. Así, en septiembre de 2017 el presidente Donald Trump anuncia el fin del programa DACA y la suspensión de dichos derechos para todos los jóvenes participantes. Más allá de la suspensión de un programa de incorporación juvenil, este tipo de decisiones en la Presidencia de los Estados Unidos propicia un panorama multidimensional de las condiciones esperadas por los jóvenes migrantes en aquella nación. Lo anterior debido a que no solamente se limita al derecho de trabajo y educación, sino que establece los antecedentes que configuran el actuar de una sociedad americana frente a las comunidades migrantes. A decir de Barros (2017, p. 131), este escenario encendió las alertas en las familias migrantes, pero también en empleadores americanos y las asociaciones que suelen colaborar con la comunidad, propiciando así que, ante el crecimiento de las amenazas y la cada vez mayor falta de oportunidades, las familias consideren el retorno a sus pueblos de origen como una medida de supervivencia.

El regreso de varias familias migrantes mexicanas al país era inminente a finales de 2017. La cautela se reflejó inmediatamente en el descenso de la cantidad de remesas provenientes de Estados Unidos; de igual manera, las cuentas bancarias a nombre de los trabajadores migrantes comenzaron a vaciarse ante la posible pérdida de los ahorros familiares. Aunado a los reflejos de carácter económico por la falta de garantías laborales para esta comunidad, comenzaron a manifestarse condiciones de incerti- 
dumbre colectiva entre los jóvenes, que veían frustradas sus aspiraciones de crecimiento en el país que los vio crecer y que, al mismo tiempo, los enviaba fuera sin una estrategia de acogida para continuar con su desarrollo (Holpuch, 2017). Por su parte, el gobierno de México ofreció dar acompañamiento y generar las condiciones óptimas para recibir a las familias provenientes de la Unión Americana, al mismo tiempo que instruyó a las autoridades de las secretarías de educación estatales para formular estrategias de inserción para niños y jóvenes en el sistema educativo mexicano.

En el caso de las comunidades indígenas purépechas, en diciembre de 2017 regresaban las primeras familias a instalarse en la comunidad de origen, algunos por decisión propia y otros en calidad de deportados, al ser detenidos en diferentes circunstancias por autoridades migratorias. Los más grandes buscaron oportunidades de ocupación (principalmente en el sector agrícola y de la construcción), pero los más jóvenes fueron los que presentaron mayores dificultades, al no contar con las condiciones de inclusión, socialización, participación y gestión en una comunidad que les seguía pareciendo ajena, situación muy similar a la de jóvenes indígenas migrantes de otras naciones latinoamericanas (Del Alamo, 2018, p. 101). Los jóvenes en retorno dieron cuenta de que las estrategias de acogida anunciadas por el gobierno del país que los recibía (México) todavía no eran operativas, es decir, eran parte de una serie de discursos que fomentaban la tranquilidad, pero que no proporcionaban las aristas tangibles para incorporar de manera óptima a los connacionales. Aunado a lo anterior, los jóvenes purépechas reconocieron que huían de una sociedad americana que los discriminaba, para regresar a una sociedad mexicana que de muchas maneras también los discrimina.

De acuerdo con diversos estudios relacionados, como el de Sánchez y Bautista, la población indígena purépecha ha sido históricamente objeto de discriminación por parte de sus connacionales mestizos. Nuevamente la diferenciación de la lengua y el sistema de creencias ha propiciado un reconocimiento parcial de 
sus garantías individuales avaladas por la Constitución Política de los Estados Unidos Mexicanos, las cuales son reconocidas en el ámbito de las leyes pero no así en la práctica (Sánchez y Bautista, 2014, pp. 115-127). En el caso de los jóvenes de edad escolar, han sido desfavorecidos principalmente en los sistemas educativos, y es que los porcentajes de jóvenes purépechas matriculados en las universidades se encuentran muy por debajo de la media. Este panorama, aunado al clima de inseguridad y de violencia que se vive en la región, propicia incluso que muchos de estos jóvenes se vean involucrados con el crimen organizado, ya sea en calidad de víctimas o en calidad de colaboradores forzados, lo que nuevamente condiciona su bienestar a un estilo de vida al borde de la ley y a los riesgos que representa estar fuera de ella (Fuentes y Paleta, 2015, p. 171).

Una vez de regreso en la comunidad que los vio nacer, los jóvenes purépechas migrantes provenientes de Estados Unidos se encuentran nuevamente con un panorama de incertidumbre para su toma de decisiones $y$, a pesar de ya no sentirse perseguidos por autoridades extranjeras, dicen tampoco confiar en autoridades mexicanas, saben poco de ellas, pero lo poco que saben lo han recibido a través de los medios de comunicación, con juicios de valoración más bien negativos de acuerdo con sus intereses. Algunos de estos jóvenes purépechas cuentan con estudios parciales de nivel superior en diferentes áreas del conocimiento; sin embargo, hacen evidente su preocupación al no encontrar una vía clara para dar continuidad a sus estudios. Además, el panorama se les complica, al no poder socializar sus problemas con jóvenes en la misma situación dentro de la comunidad, ya que son escasos, y aquellos con los cuales han logrado tratar el tema cuentan con muy poca información, debido a que verdaderamente no existe una estrategia operativa para dar seguimiento a su situación. Las dificultades que estos jóvenes enfrentan para dar continuidad a su vida productiva, a la que estaban acostumbrados, son muchas y dependen de lo político, lo normativo, lo psicosocial y hasta lo geográfico; concebir la vida en una comu- 
nidad alejada de las ciudades, con carencias de servicios y sin infraestructura educativa les suele generar diversas crisis en diferentes niveles.

Ante la no ocupación laboral de los jóvenes migrantes en la comunidad, incluso la práctica de sus pasatiempos se convierte en tema conflictivo, el skate, el breakdance, el sticker y el graffiti, entre otras, son prácticas poco conocidas en la comunidad y, en muchos casos, vistos como amenaza al orden público y al sistema de valores y creencias promovidos de manera axiomática a través de los roles en la comunidad indígena. Esta contraposición de las prácticas estimadas por la comunidad y las prácticas promovidas por el colectivo de jóvenes provenientes del extranjero ha generado desencuentros que llegan incluso a la procuración de justicia, a la prevención de delito y a violaciones a los derechos humanos por parte de autoridades en contra de los jóvenes (Guevara, 2015, p. 199). Dada esta falta de conciliación entre las perspectivas juveniles en la comunidad purépecha y la falta de foro para manifestar sus preocupaciones, los ahora nuevos residentes de la comunidad han encontrado pocas vías para la expresión de sus ideas. La radio, por ejemplo, específicamente la radio comunitaria, es una de las pocas oportunidades para la socialización de sus inquietudes y para la expresión de su sentir en un espacio plural, incluyente, abierto y hasta cierto punto tolerante, características históricamente significativas en los sistemas de radio comunitaria de la zona purépecha.

\section{Jóvenes migrantes purépechas y su perspectiva ciudadana en la comunidad indígena}

La estrategia metodológica diseñada para dar seguimiento a las indagatorias de esta investigación se estructuró con base en un trabajo descriptivo de enfoque cualitativo, incorporando el análisis de corte etnográfico como método particular, y con observación, grabaciones, entrevistas informales in situ y entrevistas a profundidad como principales técnicas de recolección de 
información. Dicho trabajo metodológico tuvo lugar durante los meses de diciembre de 2017 y febrero de 2018 en las localidades de Angahuan, Cherán, Zacán y Paracho, todas ubicadas en la meseta purépecha de Michoacán, México, y caracterizadas por su gran concentración de población indígena. El trabajo de campo incorporó en calidad de coinvestigadores a cuatro jóvenes indígenas cuya características común es haber regresado ese año a su comunidad, haber vivido la mayor parte de su vida en Estados Unidos y haber recibido la educación básica en los sistemas escolares norteamericanos.

Los jóvenes indígenas participantes en la investigación fueron contactados bajo la modalidad de bola de nieve y, a pesar de que se buscaron desde el inicio diez jóvenes, solamente se pudo trabajar con cuatro debido a la resistencia a participar que mostró el resto, por diferentes motivos ${ }^{3}$. Así, se desarrollaron labores para el proceso de análisis de corte etnográfico incorporando las miradas de los jóvenes y del investigador para la reconstrucción de algunos significados clave desde el escenario de su comunidad, considerando todos los elementos nodales y periféricos que pudiesen aportar a la interpretación del tejido social apreciado. Los jóvenes participantes fueron: Custodio, varón de la localidad de Cherán; Fermín, varón de la localidad de Zacán; María, mujer de la localidad de Angahuan, y Crisanto, varón de la localidad de Paracho, todos ellos mayores de edad y participantes de manera voluntaria.

Para los propósitos de las indagatorias sometidas al análisis en la investigación, se parte del concepto de "práctica" como categoría central, para posteriormente construir lo comunitario y lo ciudadano. Así, la "práctica" se observa como la acción que va más allá de hacer algo en sí mismo, es el hacer algo dentro de un contexto histórico y social, otorgándole estructura y significado a eso que se hace, lo que, de acuerdo con Wenger, es siempre una

La principal resistencia para la participación de otros jóvenes identificados, y de sus familias, fue motivada por la incertidumbre y el temor por las condiciones sociales que imperan en la zona. 
práctica social. Como el caso de los esfuerzos que apuntan hacia la integración comunitaria.

Este concepto de práctica incluye tanto los aspectos explícitos como los implícitos. Incluye lo que se dice y lo que se calla, lo que se presenta y lo que se da por supuesto. Incluye el lenguaje, los instrumentos, los documentos, las imágenes, los símbolos, los roles definidos, los criterios especificados, los procedimientos codificados, las regulaciones y los contratos que las diversas prácticas determinan para una variedad de propósitos (Wenger, 2001, p. 71).

En este sentido, el proceso de participación en la práctica siempre implica el todo de la persona, actuando y conociendo al mismo tiempo, y en el que acción y conocimiento forman parte del mismo objetivo y no son determinados como elementos aislados en el aprendizaje de la ciudadanía. En este orden de ideas se tiene que, desde la práctica, lo comunitario se construye como ese ejercicio de comunicación directamente vinculado con la percepción de la realidad social en la que se desarrolla, y su forma de vida deberá ser entendida con toda la complejidad implicada. De acuerdo con Varien y Potter, en la acepción de lo comunitario la observación de una forma de vida implica el entrelazamiento de sentido de los elementos normativos y de poder, y esto se hace evidente en los diferentes contextos de la vida social en los que se cuestiona el ser de los fenómenos sociales, y así, para su comprensión, se le otorga especial valor al cuestionamiento, a las caracterizaciones divergentes y a las suposiciones de la actividad cotidiana para entender esta forma de vida (Varien y Potter, 2008, p. 249).

La esencia de lo ciudadano, en el contexto de esta investigación, se comprende en esta lógica como aquello que va más allá de derechos y obligaciones, es:

La capacidad del individuo de reconocerse como parte de una comunidad, en donde su participación es trascendente para el logro de bienes comunes con la finalidad de me- 
jora de los escenarios públicos. Asumiendo la práctica de derechos y obligaciones como garantías de la democracia, y propiciando un sentido de equidad, justicia y ética en la cotidianidad de sus acciones (Fernández, 2010, p. 47).

En conjunto con lo comunitario y lo ciudadano, la práctica, como acción sustancial en el aprendizaje colectivo de la ciudadanía, es reconocida en comunidad a través de los siguientes aspectos. a) la práctica como significado, en la cual la producción social de significado es el nivel más pertinente para hablar de práctica; $b$ ) la práctica como comunidad, presentando la práctica como fuente de cohesión en una comunidad; c) la práctica como aprendizaje, entendida como proceso de aprendizaje en una estructura emergente y variable de forma constante; d) la práctica como límite, estableciendo acotaciones más allá de lo interno y de lo externo, de manera que se conciben dichos límites como un panorama complejo de periferias, y e) la práctica como situación, cuando es parte de una comunidad, o bien comienza a ser parte de una constelación de comunidades que apuntan a diversos fines (Wenger, 2001, p. 73), como los fines que se buscan para la óptima reincorporación de los jóvenes migrantes a su propia comunidad natal.

Cuadro 1. Características de los jóvenes indígenas participantes en la observación etnográfica

\begin{tabular}{|l|l|l|l|l|l|}
\hline Nombre & $\begin{array}{l}\text { Actual } \\
\text { residencia }\end{array}$ & $\begin{array}{l}\text { Estudios } \\
\text { realizados }\end{array}$ & $\begin{array}{l}\text { Beneficiario } \\
\text { DACA }\end{array}$ & $\begin{array}{l}\text { Actividad } \\
\text { laboral en } \\
\text { EE.UU }\end{array}$ & $\begin{array}{l}\text { Participante } \\
\text { de algún } \\
\text { programa en } \\
\text { México }\end{array}$ \\
\hline Custodio & Cherán & Bachillerato & 2 años & $\begin{array}{l}\text { Actividades } \\
\text { Agrícolas }\end{array}$ & Ninguno \\
\hline Fermin & Zacán & $\begin{array}{l}\text { Estudios } \\
\text { parciales de } \\
\text { Enfermería }\end{array}$ & $\begin{array}{l}\text { 0 años } \\
(2 \text { solicitudes })\end{array}$ & $\begin{array}{l}\text { Trabajo en } \\
\text { cocina }\end{array}$ & $\begin{array}{l}\text { Bolsa de } \\
\text { empleo del } \\
\text { Municipio de } \\
\text { Uruapan }\end{array}$ \\
\hline María & Angahuan & Bachillerato & 1 año & $\begin{array}{l}\text { Aseo do- } \\
\text { méstico }\end{array}$ & $\begin{array}{l}\text { Seguro } \\
\text { Popular }\end{array}$ \\
\hline Crisanto & Paracho & Bachillerato & 3 años & $\begin{array}{l}\text { Taller de } \\
\text { molduras }\end{array}$ & Ninguno \\
\hline
\end{tabular}


Con los cuatro jóvenes considerados para esta investigación se establecieron entrevistas formales e informales en el acompañamiento de sus quehaceres en su cotidianidad en la comunidad. La manera de contactarlos y de poder establecer condiciones de acercamiento con ellos se dio gracias a la importante ayuda de jóvenes purépechas matriculados en la Universidad Michoacana de San Nicolás de Hidalgo (universidad pública del Estado de Michoacán, México), quienes establecieron contacto y dieron sus referencias para formalizar una estrategia de seguimiento bajo su propio consentimiento.

La técnica de la entrevista a profundidad permitió desarrollar paulatinamente las temáticas previamente establecidas en el guion, las cuales, desde el principio, se sustentaban en el objetivo y en el supuesto de la investigación; sin embargo, la riqueza de la entrevista como técnica permitió incorporar algunos otros temas que, si bien no se consideraban como prioritarios al inicio del trabajo de campo, sí guardaban fuerte relación con las experiencias de los jóvenes participantes; así es el caso de las condiciones laborales familiares, las condiciones de socialización con sus pares en la comunidad o sus ideas preestablecidas respecto de la pertenencia al país que los vio nacer, entre otras.

El trabajo de las entrevistas se desarrolló en un promedio de diez días naturales con cada uno de los participantes, y es que el trabajo etnográfico que pretende dar seguimiento a la cotidianidad demanda de procesos de participación voluntaria, y progresiva, por parte de los involucrados. Así, se partió de conversaciones rígidas con apego riguroso al guion, obteniendo respuestas cortas y desinteresadas. Dichas conversaciones se hicieron principalmente en idioma español e inglés; lo anterior a pesar de que las cuatro comunidades seleccionadas como locación son comunidades que poseen la lengua p'urhépecha como lengua natal, lo que marcaba ya una dificultad de pertenencia por parte del joven migrante en retorno, que no dominaba la lengua de origen y prefería comunicarse en una suerte de lengua hibrida entre español e inglés. 
Durante la dinámica del trabajo de campo, transcurridos los primeros días de interacción, paulatinamente se fue haciendo presente la confianza por parte de los participantes, propiciando así la gestión de temáticas no apegadas al guion, pero sí nutritivas para la investigación. En este orden de sucesos se pudo dar evidencia del papel de los participantes en lugares públicos, las prácticas de comunicación que mantenían con la familia nuclear y la familia periférica, así como sus temores e intereses. Un elemento central que se pudo recopilar gracias a las entrevistas, tanto en su faceta estructurada como en la informal, fue la noción de "ciudadanía" que se cuestionaba y se definía a través del relato, y es que, a pesar de que no se discutió el tema de manera explícita a través de sus definiciones formales, sí se reconstruyeron conceptos desde la apreciación de los participantes; principalmente señalando derechos y prerrogativas que no se hacían presentes desde su experiencia.

Destacan entre la información obtenida, y una vez comparada entre los cuatro casos, los siguientes aspectos en común:

a) Nacieron en México y fueron llevados a Estados Unidos cuando tenían menos de 10 años.

b) Tuvieron la oportunidad de ingresar a la escuela básica en Estados Unidos, incluso refieren haber aprendido a leer y escribir en aquel país.

c) Dicen expresarse bien en inglés y español, pero reconocen escribir mejor el inglés que el español.

d) Se consideran incapaces de escribir el p'urhépecha.

e) Todos expresan haber anhelado hacer carrera en Estados Unidos, y

f) Manifiestan verdadera preocupación por no saber cuál será su paradero en México.

En el caso de María, la única mujer entrevistada, se detecta en sus relatos mucho énfasis en las condiciones de discriminación, no solamente por su calidad de migrante, sino también por la de mujer, debido a un evidente discurso opresivo de género. María 
hace ver, por ejemplo, cómo su propia familia le generó obstáculos para seguir estudiando. Así, relata:

Cuando la maestra me entregó el diploma de la basic school yo estaba muy emocionada porque había salido como una de las mejores de la clase, y entonces le platiqué a mi mamá que estaba preocupada porque mis amigas estarían en otra escuela, en eso se metió mi hermano y me dijo que yo ni me preocupara porque pa tener hijos y andar trabajando en las casas no se ocupaba estudiar, nomás se ocupaba no hacer escándalo para no echarse de ver por la Migra... [SIC] (María, Angahuan, 2017).

Así como en el anterior ejemplo, María, durante las entrevistas, hace referencia a comentarios, insultos, limitaciones y prohibiciones por parte de mucha gente, incluidos miembros de su familia, y reconoce en el profesorado y en algunas empleadoras americanas el apoyo para poder seguir estudiando. Aunado a lo anterior, María relata con mucha apertura que ella se enteró del programa DACA gracias a una ciudadana americana que le dotó de toda la información. El papel de las familias, como agente mediador para la toma de decisiones en los jóvenes migrantes, fue fundamental, y es que en la mayoría de los casos se configuran verdaderas crisis de negociación para la toma de decisiones en búsqueda de su continuidad, como fue el caso de Custodio, quien comparte la experiencia y dice:

Una vez yo dije lo del DACA mientras comíamos el lunch en la parcela, como para tantear lo que mi papá decía de eso, y luego luego que se hace la alegata entre mis hermanos, primos y todos los que trabajaban, unos me decían: tas loco, eso nomás es una trampa del gobierno para que tú les digas cuánto llevas aquí, con quién vives, en dónde vives, y un buen día de estos, tan tan, cae la migra a tu casa y van a parar todos al bote [cárcel], y a mí pues sí me daba miedo que por mi culpa fueran a agarrar a mi papá o hermano [SIC] (Custodio, Cherán, 2017). 
El miedo y la falta de certidumbre es una constante que manifestaron los entrevistados, principalmente referidos al caso de brindar su información a través de su solicitud de participación en el programa DACA, debido a que la solicitud de participación en dicho programa americano implicaba la presentación de muchos documentos con información de tipo personal del interesado, aunado a la respectiva confirmación y cotejo de la información por parte del Departamento del Homeland Security. En las respectivas entrevistas, Custodio refiere que, a pesar del miedo, integró su solicitud gracias a la asesoría que encontró en un ministro de la iglesia protestante, quien lo asesoró a través de la Casa del Migrante Michoacano en Chicago.

La revisión de los documentos presentados en la solicitud para la participación en el programa DACA fue en todos los casos un tema sensible, ya que consistía en poner a disposición de las autoridades norteamericanas toda la información relacionada con identidad e historial personal del interesado, y en parte de sus familias. Fermín asume que en todas las ocasiones en las que solicitó participar en el programa, fue rechazado debido a su historial registrado en Estados Unidos, y es que dice haber sido deportado en el primer intento de cruzar la frontera junto con su familia cuando él apenas tenía seis años, además de contar con varios familiares que habían sido detenidos en algún momento, o bien también deportados. Por otro lado Crisanto, otro joven indígena que sí fue beneficiario del programa DACA, reporta que él reconoce como gran ventaja la opinión que proporcionaron de él los diferentes empleadores con los que había podido trabajar, al respecto expone:

Yo tuve la suerte de trabajar en varios talleres de carros, motos, botes y así varios, y en los talleres los dueños casi siempre son güeros [ciudadanos estadounidenses] y con muchos de ellos me llevaba bien, entonces yo siento que cuando les preguntó el gobierno sobre mí han de haber dicho cosas buenas y supongo que eso me echó la mano para que me dieran chance [oportunidad] de seguirle en la escuela [SIC] (Crisanto, Paracho, 2018). 
Durante el trabajo etnográfico que se realizó en acompañamiento y cooperación de los jóvenes indígenas, se logró registrar más de 40 horas de conversaciones formales e informales, las cuales se resguardaron en dispositivos magnéticos en formatos de audio y video; a su vez, dichas conversaciones se revisaron constantemente, para generar una selección de categorías centrales de análisis que sí estuvieron presentes en los relatos de los jóvenes colaboradores. Aunado a lo anterior, se seleccionaron las conversaciones más ricas en relación con el objeto de estudio para realizar transcripciones, las que permitieron, a su vez, identificar el empleo de algunos símbolos que dan noción de la práctica y preocupación por la ciudadanía por parte de estos jóvenes. Algunos de estos símbolos empleados en el contexto de los jóvenes se daban en lengua española, y otros tantos en inglés.

Cuadro 2. Ejemplo de categorías analíticas y marcadores discursivos en los relatos de los jóvenes purépechas

\begin{tabular}{|c|c|c|c|}
\hline $\begin{array}{l}\text { Categoría } \\
\text { Identifi- } \\
\text { cada }\end{array}$ & $\begin{array}{l}\text { Extracto } \\
\text { Conversacional }\end{array}$ & $\begin{array}{l}\text { Marcadores } \\
\text { discursivos }\end{array}$ & $\begin{array}{l}\text { Observaciones / Infe- } \\
\text { rencias }\end{array}$ \\
\hline $\begin{array}{l}\text { Contraste } \\
\text { de respeto } \\
\text { a las } \\
\text { garantías } \\
\text { individua- } \\
\text { les en un } \\
\text { país y otro }\end{array}$ & $\begin{array}{l}\text { Allá se quedaron } \\
\text { mis amigos, allá sí } \\
\text { se hacía buena la pa- } \\
\text { changa, es que allá no } \\
\text { hay problem de que te } \\
\text { agarren los cops with } \\
\text { beers en la calle. Aquí } \\
\text { hasta por fumar te } \\
\text { quieren llevar, allá es } \\
\text { la cosa más normal... }\end{array}$ & $\begin{array}{l}\text { Allá: } \\
\text { adverbio de } \\
\text { lugar utili- } \\
\text { zado como } \\
\text { sinónimo } \\
\text { de Estados } \\
\text { Unidos. }\end{array}$ & $\begin{array}{l}\text { Adverbio constante- } \\
\text { mente utilizado en las } \\
\text { conversaciones por los } \\
\text { jóvenes entrevistados } \\
\text { y sus familias. No } \\
\text { solamente se emplea } \\
\text { para señalar geográfica- } \\
\text { mente, sino para hacer } \\
\text { referencia a un periodo } \\
\text { del pasado de sus vidas. }\end{array}$ \\
\hline $\begin{array}{l}\text { Condiciones } \\
\text { de intercul- } \\
\text { turalidad y } \\
\text { presunción } \\
\text { de inocencia }\end{array}$ & $\begin{array}{l}\text { La gente me mira mal } \\
\text { cuando salgo con mi } \\
\text { skate, la otra vez una } \\
\text { señora hasta me dijo } \\
\text { que me iba a echar a } \\
\text { la policía; } \\
\text { - y le pregunté ¿por } \\
\text { qué? } \\
\text {-Y me dijo que por } \\
\text { mariguano... }\end{array}$ & $\begin{array}{l}\text { Mariguano: } \\
\text { adjetivo que } \\
\text { señala, no } \\
\text { prácticas } \\
\text { de consu- } \\
\text { mo, sino } \\
\text { acusaciones } \\
\text { de criminali- } \\
\text { dad. }\end{array}$ & $\begin{array}{l}\text { El empleo de adjetivos, } \\
\text { principalmente relacio- } \\
\text { nados con condiciones } \\
\text { de vandalismo y crimi- } \\
\text { nalidad aparecen mucho } \\
\text { en el pesar de los jóve- } \\
\text { nes. Principalmente hay } \\
\text { una asociación cuando se } \\
\text { trata de prácticas no co- } \\
\text { munes en la comunidad. } \\
\text { (ejemplos: brake dance, } \\
\text { grafiti y skate board). }\end{array}$ \\
\hline
\end{tabular}




\begin{tabular}{|c|c|c|c|}
\hline $\begin{array}{l}\text { Condiciones } \\
\text { de seguri- } \\
\text { dad para el } \\
\text { ejercicio de } \\
\text { su libertad } \\
\text { y la bús- } \\
\text { queda de la } \\
\text { calidad de } \\
\text { vida }\end{array}$ & $\begin{array}{l}\text { Nombre! Ahí se las } \\
\text { lleva la maña a punta } \\
\text { de carabina, mi } \\
\text { hermana me contó } \\
\text { que cuando fueron a } \\
\text { Uruapan luego luego } \\
\text { [SIC] se les arrima- } \\
\text { ron los amigos para } \\
\text { decirles de cosas y } \\
\text { amenazarlas... }\end{array}$ & $\begin{array}{l}\text { Maña / Los } \\
\text { Amigos: } \\
\text { modali- } \\
\text { dad para } \\
\text { llamar a los } \\
\text { miembros } \\
\text { del crimen } \\
\text { organizado } \\
\text { en la zona, } \\
\text { principal- } \\
\text { mente narco- } \\
\text { traficantes. }\end{array}$ & $\begin{array}{l}\text { El crimen organizado, la } \\
\text { violencia y el narcotrá- } \\
\text { fico es un tema muy } \\
\text { presente en los relatos } \\
\text { de los jóvenes colabora- } \\
\text { dores. Y a pesar de que } \\
\text { no han tenido contacto } \\
\text { con este sector, manifies- } \\
\text { tan estar muy informa- } \\
\text { dos de la problemática y } \\
\text { de la amenaza constante } \\
\text { que representa para } \\
\text { ellos y sus familias. }\end{array}$ \\
\hline $\begin{array}{l}\text { Derecho a } \\
\text { la educa- } \\
\text { ción para el } \\
\text { desarrollo } \\
\text { económico } \\
\text { y personal }\end{array}$ & $\begin{array}{l}\text { Cuando salí de la } \\
\text { high school si pensa- } \\
\text { ba seguirle, a mí me } \\
\text { iba muy bien, y luego } \\
\text { busqué algunas aquí } \\
\text { y me dijeron que la } \\
\text { única que estaba reci- } \\
\text { biendo era una high } \\
\text { school en Morelia, } \\
\text { pero que solamente } \\
\text { recibía para morros } \\
\text { que ya estaban en el } \\
\text { bachelor... }\end{array}$ & $\begin{array}{l}\text { High school: } \\
\text { sustantivo } \\
\text { en inglés } \\
\text { que, aunque } \\
\text { se tradu- } \\
\text { ce como } \\
\text { bachillerato, } \\
\text { es princi- } \\
\text { palmente } \\
\text { utilizado } \\
\text { para referir } \\
\text { al sistema } \\
\text { escolarizado. }\end{array}$ & $\begin{array}{l}\text { Las referencias a la edu- } \\
\text { cación se detectan en las } \\
\text { conversaciones como } \\
\text { una constante situación } \\
\text { de desventaja al estar } \\
\text { en México, a diferencia } \\
\text { de cuando estaban en } \\
\text { Estados Unidos. Acusan } \\
\text { abiertamente no ser } \\
\text { incluidos en alguna } \\
\text { opción para estudiar en } \\
\text { su comunidad. }\end{array}$ \\
\hline $\begin{array}{l}\text { Oportuni- } \\
\text { dades de } \\
\text { ocupación } \\
\text { laboral y } \\
\text { crecimiento } \\
\text { económico }\end{array}$ & $\begin{array}{l}\text { O sea que a veces sí } \\
\text { hay jale pero pagan } \\
\text { muy poquito, y ya de } \\
\text { por sí mi hermano } \\
\text { anda apurado por } \\
\text { sacar jalesillos pa él } \\
\text { [...] En eso debería de } \\
\text { pensar el gobierno, si } \\
\text { le da jale a la gente se } \\
\text { ahorra la mitad de las } \\
\text { broncas... }\end{array}$ & $\begin{array}{l}\text { Jale: } \\
\text { modalidad } \\
\text { de nombrar } \\
\text { la actividad } \\
\text { laboral, no } \\
\text { contratación } \\
\text { permanente, } \\
\text { sino trabajos } \\
\text { temporales } \\
\text { que surgen } \\
\text { para contra- } \\
\text { tación de sus } \\
\text { servicios. }\end{array}$ & $\begin{array}{l}\text { La actividad laboral } \\
\text { que reconocen los } \\
\text { jóvenes incorporados } \\
\text { a la investigación está } \\
\text { referida en términos de } \\
\text { contrataciones tempo- } \\
\text { rales en función de sus } \\
\text { habilidades- Parece no } \\
\text { haber una noción de } \\
\text { una contratación con } \\
\text { prestaciones, lo que } \\
\text { a su vez apunta a las } \\
\text { prácticas laborales a las } \\
\text { que estaban acostum- } \\
\text { brados en su calidad de } \\
\text { migrantes. }\end{array}$ \\
\hline
\end{tabular}

Así como se puede apreciar en el cuadro 2, la relación entre las categorías analíticas y los marcadores discursivos empleados por los jóvenes indígenas participantes permitió generar una serie de inferencias que dieron cuenta de un panorama suscitado en una 
realidad relatada por los propios jóvenes. Dichos relatos hacen evidentes sus preocupaciones, pero también sus denuncias ante un sistema de procuración ciudadana que no les garantiza la equidad, la seguridad y la inclusión en el tejido social del país que les vio nacer.

Los jóvenes participantes socializaron, mediante sus conversaciones y referencias, aspectos de significación, y de pugna, vinculados a su noción de "ciudadanía" y que no reconocen garantizados en su propio país al cual han tenido que retornar. Entre estos aspectos, hacen énfasis mayoritariamente a los siguientes (principalmente relacionados con derechos avalados por la Constitución Política de los Estados Unidos Mexicanos):

a. Derecho a la igualdad, en su trato y en sus aspiraciones de crecimiento personal;

b. Derecho a la educación laica y gratuita;

c. Derecho a un trabajo digno;

d. Derecho a la participación en los asuntos públicos, y

e. Derecho a la libre asociación y manifestación de las ideas.

\section{Inferencias y conclusiones sobre la apreciación ciudadana de los jóvenes purépechas migrantes}

Durante los diferentes meses de trabajo en las comunidades indígenas purépechas de Paracho, Zacán, Angahuan y Cherán, se dio la oportunidad de contextualizar la situación de algunas nociones de "ciudadanía" por parte de los jóvenes connacionales en retorno, no solamente a través del discurso, sino mediante el reconocimiento de diferentes aristas relacionadas, como las del espacio geográfico, la observación social, la disposición de los recursos y la inclusión en las dinámicas de organización, entre otras. Mediante el registro de las experiencias surgieron también nuevas inquietudes e indagatorias que inicialmente no se contemplaban en la investigación; sin embargo, sí generaron miradas complementarias que propiciarían el crecimiento del estado de la cuestión y su constante apreciación desde diversas disciplinas. 
Se aprecia, a través de los relatos, la expresión de inconformidad de los jóvenes purépechas migrantes por haberse visto obligados a retornar a sus comunidades de origen. Si bien ellos reconocen haber sido objeto de abusos e injusticias mientras se encontraban en calidad de migrantes ilegales en Estados Unidos, también reconocen que se sentían con más esperanzas y entusiasmo en aquel país. Dicha inferencia se manifiesta en la manera que ellos relatan sus expectativas de crecimiento laboral, en constante comparación entre su periodo de trabajadores migrantes en Estados Unidos y la búsqueda de oportunidades de inserción laboral en sus comunidades de origen. Adicionalmente, llama la atención el tema a la luz de un discurso calificado como "riguroso" en contra de las comunidades migrantes por parte de la clase gobernante de la Unión Americana, pero, a pesar de ello, estos jóvenes se dicen dispuestos a probar una nueva oportunidad para retomar la vida que los identificaba durante su estancia como inmigrantes en aquel país. Esta realidad se puede describir desde la evidencia de la falta de oportunidades que este segmento demográfico sigue viviendo, al reconocerse como ciudadano mexicano indígena, en contraste con las oportunidades que dice haber obtenido como trabajador ilegal. El cuestionamiento sería entonces: ¿es mejor opción para estos jóvenes indígenas la vida en ilegalidad en Estados Unidos o la vida en desigualdades en su propio país?

Ante la contundencia de las decisiones en las políticas migratorias de la actual presidencia de los Estados Unidos, el gobierno mexicano generó una serie de posicionamientos para brindar tranquilidad y certidumbre a los connacionales en condiciones ilegales en el vecino país. Así, instruyó a consulados y oficinas de enlace a brindar información, orientación y apoyo jurídico a los que así lo requirieran, para salvaguardar su patrimonio y el respeto a los derechos humanos. Adicionalmente, los gobiernos estatales en México hicieron los propios posicionamientos y anunciaron las medidas a implementar, principalmente en el ámbito migratorio, laboral y educativo, para recibir a los mexicanos en movilidad internacional; lo anterior con especial atención a los jó- 
venes en edad escolar (Gobierno del Estado de Michoacán, 2017). Sin embargo, la realidad relatada por los jóvenes purépechas fue muy distinta a las declaraciones de la clase gobernante mexicana. A pesar del despliegue mediático y de diplomacia en términos de política internacional por parte de los políticos mexicanos, los jóvenes colaboradores con esta investigación denuncian no haber recibido ningún tipo de apoyo, ni por los consulados en Estados Unidos, ni por las oficinas de apoyo al migrante una vez en México. Reconocen que el gobernador del Estado de Michoacán se manifestó constantemente al respecto a través de los medios de comunicación; sin embargo, señalan dichas declaratorias como parte de una estrategia meramente política, contraria a la experiencia que ellos han vivido, debido a que no encuentran vías que les ofrezcan certeza para continuar con su desempeño educativo o laboral en México.

Ante las constantes acusaciones contra la falta de garantías por parte de los gobernantes mexicanos para salvaguardar los derechos de los connacionales, las cuales fueron detectadas en el discurso de los jóvenes participantes a través de los comentarios, entrevistas y conversaciones con otros miembros de su familia, se torna evidente que las medidas adoptadas por la administración pública competente en esta materia responden más a una reacción ante las inesperadas medidas de las políticas migratorias en Estados Unidos. que a una verdadera planeación estructural para inclusión de jóvenes mexicanos en calidad de migrantes en otras geografías. Llama la atención también el papel limitado de las secretarías de Estado para agregarse a la solución del problema; por su parte, los jóvenes indígenas enlistan varias oficinas de instancias a las que ha acudido en búsqueda de información, refieren el mal trato con el que se les ha atendido y en la mayoría de los casos relatan una evidente falta de información y desconocimiento de los protocolos para ofrecer la presunta inclusión por parte de las estructuras del Estado. Cabe señalar que dicha acusación no solamente sucede en el caso de los indígenas migrantes en retorno, se trata de una acusación constante que por décadas se ha 
manifestado en las comunidades indígenas en busca del acceso a la salud, la educación y la representación política en México.

La inequidad con la que se atiende a la población indígena en los servicios públicos mexicanos, como se ha dicho, no es un problema nuevo ni propio de los indígenas en condición migrante, es más bien una resistencia por la segmentación de derechos por parte de ciertos sectores representados en la clase gobernante, lo cuales, por un lado, resaltan la imagen del indígena de los grandes imperios históricos (Azteca, Maya, y Purépecha, entre otros) y, por otro, propician prácticas de distinción en derechos y garantías individuales. Así como señala Korsbaek, un elemento por el cual muchos indígenas mexicanos sufren distintas modalidades de discriminación es la lengua natal (diferente del español), caso muy parecido a lo que sucede en otras geografías de América Latina (Korsbaek, 2017, p. 429), y en el caso de los jóvenes indígenas migrantes la complejidad de la lengua se multiplica ante el contraste en el que los ha obligado a interactuar cada contexto temporal.

Durante el trabajo de campo se pudo observar que los jóvenes purépechas en retorno reflejan en sus relatos y experiencias verdaderas dificultades para desarrollar las tareas más básicas en la comunidad a la que han regresado, señalan las grandes diferencias que existen en sus intentos de comunicación con jóvenes de su edad, con otros adultos, con autoridades, con la burocracia, con las fuerzas del orden y hasta con familiares. Dicen hacer esfuerzos por comunicarse en español, pero encuentran que muchos adultos solamente son hablantes del purépecha y que algunos burócratas no entienden su variante dialectal del español. Ante este panorama, se observa una dificultad muchas veces señalada, pero que sigue sin ser contemplada como elemento medular para el desarrollo de políticas eficientes de inclusión intercultural, las cuales, a su vez, pudieran propiciar dinámicas de empatía, tolerancia y pluralidad.

La discriminación -y racismo- que acusan los jóvenes indígenas colaboradores en la investigación a través de sus relatos, 
son realidades asimiladas como parte de un profundo problema arraigado en sus sociedades y que es representado en cada aspecto de la vida cotidiana, incluso en el desenvolvimiento de las nuevas generaciones. Como ejemplo hacen mención del acoso y burlas que suelen sufrir por parte de otros jóvenes de su edad, que señalan su manera diferente de vestir, su manera de hablar, el tipo de música que escuchan y el tipo de actividades que practican. La discriminación no para en las burlas por parte de sus connacionales, sino que los jóvenes indígenas en retorno la reconocen como parte medular de la problemática que, a su vez, se vincula con otras aristas sociales, como las de inclusión a los sistemas escolarizados o las oportunidades laborales. Reconocen perfectamente que, a través de la socialización, los jóvenes de la comunidad aprovechan oportunidades ocupacionales o participaciones en actividades formativas de tipo artísticas, culturales y deportivas, todas las anteriores condiciones presumidas por su fomento a través de los gobernantes, pero de las cuales también se consideran excluidos dichos jóvenes, lo cual focaliza la atención en el tema debido a que son aristas básicas para la dinámica del tejido social de la comunidad.

El trabajo de etnografía con los jóvenes indígenas participantes permitió dar cuenta de parte de sus realidades vigentes, realidades que fueron reconstruidas en colaboración con el entorno, con los escenarios de los espacios, con la participación de los otros, con las incorporaciones cotidianas, con tantas cosas que se dicen y también tantas cosas que se callan. Así, se reconstruyeron relatos enriquecidos por gran cantidad de símbolos que, de a poco, generaron significativas aportaciones en sus distintos formatos. Los esfuerzos para el desarrollo de esta investigación de corte etnográfico tuvieron el objetivo de aportar una mirada a la realidad sentida por los protagonistas; sin embargo, se considera que otra de las aportaciones valiosas de esta investigación pudiera ser la apertura de nuevas y pertinentes indagatorias: como las relacionadas con el tema jurídico en el caso de las políticas sociales, como las de la implementación en condiciones de equi- 
dad, como las de continuidad en relación con el indígena que no emigra pero que sí es objeto de las mismas carencias, entre otras. Finalmente, se propicia en este documento la invitación para enriquecer el estado de la cuestión, de manera abierta y multidisciplinaria, ante un panorama compartido entre algunos países en vías de desarrollo de América Latina.

\section{Referencias}

Aquino, A. (2015). "Porque si llamas al miedo, el miedo te friega": La ilegalización de los trabajadores migrantes y sus efectos en las subjetividades. Estudios Fronterizos, 16, 75-98.

Barros, M. (2017). Los efectos del DACA en la carrera profesional y las emociones de jóvenes migrantes. Estudios Fronterizos, 18, 131-148.

De la O, M. E. (2017). Los dreamers mexicanos en Estados Unidos: escenarios de coyuntura. Coyuntura Demográfica, (12), 35-39.

Del Alamo, O. (2018). El regreso de las identidades perdidas: movimientos indígenas en países centro-andinos. (Tesis Doctoral, Universidad Pompeu Fabra, Barcelona, España). Recuperado de: https://www.tdx.cat/bitstream/handle/10803/7241/toap.pdf;jsessionid=DFEA1A31FDEF9 AB21509195986219309? sequence $=1$

Farías, A. (2017). Indigenous Women and Learning Experiences about Creative Economies Related with the Sustainable Development in Angahuan Mexico. Journal of Business and Economics, 8, 66-73.

Fernández, A. (2010). Formación de ciudadanía e identidad. Voces de la sociedad civil. México DF: Ed. Universidad Pedagógica Nacional.

Flores, R. (2016). Dreamers prepare for fight against Trump. CNN Politics. Recuperado de: https:/ /edition.cnn.com/2016/12/22/politics/dreamers-trump-immigration/index.html

Fuentes, A. y Paleta, G. (2015). Violencia y autodefensas comunitarias en Michoacán, México. Íconos. Revista de Ciencias Sociales, (53), 171-186.

Gobierno del Estado de Michoacán. (2017, septiembre). Mensaje del Gobernador Silvano Aureoles Conejo. Entrega del Segundo Informe de Gobierno al Poder Legislativo. Recuperado de: 
http://michoacan.gob.mx/informes/2017/mensaje.pdf

Guevara Sánchez, B. (2015). Pandilleros indígenas: el caso de la comunidad purépecha de Angahuan. Cuicuilco, 22, 193216. Recuperado de http://www.scielo.org.mx/scielo. php?script=sci_arttext\&pid=S0185-16592015000100011\&ln $\mathrm{g}=\mathrm{es} \&$ tlng=es

Holpuch, A. (2017). Raised in America, now back in Mexico: 'The country I loved kick me out'. The Guardian. Recuperado de: https://www.theguardian.com/us-news/2017/sep/06/ undocumented-mexicans-raised-in-america-daca-dreamers

Korsbaek, F. (2017). El derecho indígena en México. Avances y Obstáculos. Alegatos Revista, 31, 419-436.

Leco, C. (2009). Migración indígena a Estados Unidos. Purépechas en Brunsville, Norte Carolina. Morelia.Ed. Universidad Michoacana de San Nicolás de Hidalgo.

Sánchez, M. \& Bautista, M. (2014). Experiencias migratorias en indígenas purépechas en Nezahualcóyotl, Estado de México. Revista Trabajo Social, UNAM, 6, 115-127.

Varien, M. \& Potter, J. M. (2008). The social construction of communities: Agency, structure, and identity in the Prehispanic Southwest. Lanham: Rowman \& Littlefield Publishers.

Wenger, E. (2001). Comunidades de práctica: Aprendizaje, significado e identidad. Barcelona: Paidós. 